\title{
Facilitating learning at conferences
}

\section{Ib Ravn* and Steen Elsborg}

Department of Education,

Aarhus University,

Tuborgvej 164, 2400 Copenhagen NV, Denmark

Email: ravn@dpu.dk

Email: se@ldi.dk

*Corresponding author

\begin{abstract}
The typical conference consists of a series of PowerPoint presentations that tend to render participants passive. Students of learning have long abandoned the transfer model that underlies such one-way communication. We propose an alternative theory of conferences that sees them as a forum for learning, mutual inspiration and human flourishing. We offer five design principles that specify how conferences may engage participants more and hence increase their learning. In the research-anddevelopment effort reported here, our team collaborated with conference organisers in Denmark to introduce and facilitate a variety of simple learning techniques at 301 - and 2-day conferences of up to 300 participants each. We present ten of these techniques and data evaluating them. We conclude that if conference organisers allocate a fraction of the total conference time to facilitated processes that engage participants in various forms of reflective conversation and knowledge sharing, they may enhance the satisfaction and learning-related outcomes experienced by their participants.
\end{abstract}

Keywords: conferences; meetings; learning; learning techniques; participation; facilitation; reflection.

Reference to this paper should be made as follows: Ravn, I. and Elsborg, S. (XXXX) 'Facilitating learning at conferences', Int. J. Learning and Change, Vol. X, No. Y, pp.xx-Xx.

Biographical notes: Ib Ravn, $\mathrm{PhD}$, is an Associate Professor at the Department of Education at Aarhus University, Denmark. His research focuses on the facilitation of learning and knowledge processes between people in organisations. He consults on knowledge sharing, meeting design and facilitation to private and public companies and has authored five books, most recently Facilitation: Managing Meetings that Create Value and Meaning (2011, in Danish)

Steen Elsborg, MSc, is a researcher affiliated with the Department of Education and Director of LDI - Learning-Driven Innovation. His specialties are facilitation, competence development, organisational learning and innovation. He has authored four books; one is Learning Meetings and Conferences in Practice (with Ib Ravn) (Copenhagen, People's Press, 2007). 


\section{Ravn and S. Elsborg}

\section{Introduction}

Conferences are a source of knowledge and inspiration to many managers, professionals and other office workers. Attending a full-day conference put on by a government agency, professional association or commercial conference organiser is a common avenue for professional development.

As anyone who attends such conferences knows, they typically consist of a series of 15-40 minute presentations followed by 5-10 minute periods for questions and answers. Considering what is known about learning today, we may well question the efficacy of such massive one-way communication. While there has been extensive experimentation practically everywhere else in the educational world, the conference, viewed as a forum for learning, stills largely pegs the learner in the role of a passive receiver of information.

The purpose of the research presented in this paper was to design and test alternatives to the classical conference format. Presented with an opportunity to experiment with conferences convened by corporate and professional meeting organisers, our group conducted a research-and-development project to test a number of learning techniques that activate and involve conference participants so as to help them learn more.

We were inspired by a group of Danish hospitality executives to use the terms 'learning meeting' (Ravn, 2007, p.213) and 'learning conference'. We deepened the meaning of this concept by devising a theory of the conference as a forum for 'human co-flourishing', and we formulated four design principles for learning meetings or conferences. A dozen processes and activities intended to enhance the participants' learning at conferences were derived from or related to these four principles. In collaboration with some of the Danish venues and their corporate clients, we implemented these techniques and evaluated their results, as reported below.

\section{The traditional conference}

Conferences come in many forms, such as diplomatic conferences (Capes, 1960; Schechter, 2001), electronic conferences (Weedman, 1999), and scientific congresses. Search conferences, dialogue conferences (Nielsen, 2006) and other large group interventions (Bunker and Alban, 1996) such as world café methods (Brown et al., 2005) gather people for consensus building, strategising and decision-making around a shared concern. This corporate or collective orientation makes such events different from our focus on the type of conference that caters to knowledge-seeking individuals from many different organisations.

Conferences that focus on knowledge-sharing and learning have been studied by a group at North Carolina State University (NCSU) (Hatcher et al., 2006; Chapman et al., 2007; Wiessner et al., 2008). They argue that little attention is paid to the learning that may (or may not) take place at conferences and suggest that conference evaluation needs to focus much more on this fact. They propose and implement a comprehensive approach to the evaluation process called New Learning, so called because of the emphasis on capturing, through many varied data collection methods, the multiple kinds of learning that may occur at the case conferences they study. The present paper shares the NCSU 


\section{Facilitating learning at conferences}

group's interest in learning at conferences, but delves into the specific kinds of individual-reflexive or social-interactive process that may be executed at conferences to facilitate learning.

Note that the object of study here is not the scholarly conference, where scores or hundreds of participants give presentations to each other (and would typically not get their way paid or attend if they could not present, which fact limits innovation seriously), but the conference for professionals and informed laypeople who come to learn by listening to half a dozen experts or so. Against this type of 'professional conference' we wish to posit six points of critique:

1 Too much lecturing: The focus is on the message that a speaker wishes to convey, not on participants' outcomes, which, consequently, are unclear.

2 Too little time for digestion and reflection: There is very little time or opportunity for the audience to reflect on the information provided or relate it to their own experience.

3 Group work at conferences is often frustrating: Groups are often fairly large, 6-10 people, with no one to facilitate. The purpose is often just to discuss a topic for its own sake, not to produce anything. The conversation tends to be dominated by the few extroverts in the group, while the remaining group members disengage.

4 The workshop is a misnomer: Parallel sessions are often called workshops. Of course, little real work gets done, and no other learning methods are used; they are simply the organisers' way of fitting more lectures in.

5 The panel of experts is just more one-way communication: A panel is often composed of experts who were not invited to present, so they are eager to get their points across. The format only appears interactive: For every question taken from the audience, several panelists often feel called upon to provide extensive answers.

6 The 'Networking lunch' is not: Simply calling a lunch, a break or a reception a 'networking event' does not make it so. Learning does indeed involve acquiring the contacts and seizing the opportunities that will expand one's range of successful action, but conference organisers typically offer very little help to participants in this regard beyond the provision of food and drink.

As is evident from these points, the assumptions about learning underlying the traditional conference are those of the transfer model, well-known from classroom teaching (Illeris, 2004) and mathematical communication theory (Shannon and Weaver, 1949). Information has been transmitted successfully and learning has taken place when information from the active sender, as encoded in the message, has been absorbed in exactly the same form by the passive receiver.

This model and its various assumptions about the human mind have been critiqued extensively over the past decades: the mind is no tabula rasa (Pinker, 2002), empty knowledge container (Illeris, 2004) or passive information storage device (Dreyfus and Dreyfus, 1986). Let us accept the well-known fact of its shortcomings and move on to consider an alternative conceptualisation of learning that is suitable to the conference as a learning forum. 


\section{Theory and design principles: the conference as a forum for human co-flourishing}

If human beings are not empty vessels to be filled with knowledge, what are they? One classical model holds that everyone possesses potentials that need to be unfolded. Aristotle $(1962$, I, 7) found the telos of human life to be eudaimonia, human flourishing (Paul et al., 1999), the blossoming of every talent and virtue a person might possess.

In modern terms, we may say that people hold innate needs and potentials that call for expression and realisation (Maslow, 1968; Deci and Ryan, 2000). If needs go unsatisfied or potentials are thwarted, physical and psychological suffering ensues (UNDP, 2005). To be human is to realise one's potentials - for thought, feeling, locomotion, communication, responsible action, etc. In this view, to learn is to become better able to meet one's needs and realise one's potentials. Learning is about acquiring action knowledge in the pragmatic sense of being able to act with still more intelligence and efficacy (Dewey, 1929; Argyris, 1982; Schon, 1983). Our learning is greatest where our potentials for successful action are experienced as most pressing, that is, in our zone of proximal development, where we are just about to go (Vygotsky, 1978).

Motivation and relevance have long been central concepts in psychology and educational theory, and they remain pertinent: Facts that a learner experiences as irrelevant are not easily picked up. If learners are unable to relate the material taught to the projects they want to pursue, that is, to the realisation of their personal or professional potentials, their learning is suboptimal.

These are some basic points about human learning established over the past century or so. Various forums for learning have been studied extensively: the classroom, the kindergarten, the shop floor, the office, the training and development programme - but apparently not the conference. Elsewhere, we have expanded on the learning-theoretical basis for the conference (Ravn, 2007; Elsborg and Ravn, 2007). For here, suffice it to say that in its capacity as a social venue for people seeking new knowledge, a conference may be seen as a forum for personal learning and mutual inspiration and, more generally, human co-flourishing.

If a conference really were to be a forum for such co-flourishing, what should it look like? What elements must a conference feature so as to stimulate the kind of learning that helps people pursue their projects, unfold their potentials and flourish as humans? Using the experience of our hospitality executives, we formulated four design principles for a learning conference (after the research, we added a fifth, to which we will return):

1 Concise presentations: Presentations should be concise, provocative, few and properly spaced, so as to provide time for reflection and learning. Research indicates that after some 30 minutes of lecturing, audience attention falls off (Bligh, 2000).

2 Active interpretation: Participants must be given opportunities to engage in active interpretation and discussion of the information provided by the presentation. They must have time and occasion to relate it to their ongoing concerns, to test it in their minds and examine it in the light of what they already know and what they want to accomplish professionally. A brief Q-and-A session for a hundred people that lets three of them ask a question is not enough. 


\section{Facilitating learning at conferences}

3 Self-formulation: The conference must offer opportunities for participants to talk about the interests and experience that made them sign up for the conference in the first place. If this content is ignored, participants will feel excluded and bored and leave by mid-afternoon, as they frequently do.

4 Networking and knowledge sharing: There must be processes and activities that help participants find people they are likely to enjoy meeting and sharing knowledge with.

\section{Methodology: testing learning techniques}

Armed with this Aristotle-inspired theory of learning and the associated design principles, we recruited five meeting organisers and meeting venues in order to obtain access to large meetings and conferences where aspects of the theory could be tested. Is it possible to implement design principles such as these and create conferences that are more like forums for human co-flourishing than traditional conferences? This was our research-and-development question.

As is apparent, our approach is akin to action research, in that we seek to take action and transform some small part of the world as we engage in research on it. Elsewhere, we have detailed the 'transformative' methodology used (Baburoglu and Ravn, 1992; Ravn, 2005); the present section merely summarises it. This approach is paralleled by other recent innovations in social research methodology, such as design-based research in educational inquiry (Cobb et al., 2003), intervention research in the field of social services (Rothman and Thomas, 1994) and design science in organisational research (Romme, 2003; van Aken, 2005). All these approaches assume that social researchers can do more than describe and explain social reality; they can and should help improve it.

Our partners were three Danish hotels, one congress centre and one large bank, which was a major customer at some of the hotels. We were given access to 30 conferences with some 100-300 participants in each. The conferences included an orientation session for new employees in the bank, one-day regional 'growth' conferences for the bank's customers, two-day professional-education conferences for social workers, healthcare professionals, IT-specialists and lawyers, the annual meeting for a corporate sports association and annual half-day meetings where the CEO presented strategy to the rankand-file.

Our group at Learning Lab Denmark included two process consultants, ${ }^{1}$ one researcher (the second author) and the project director (the first author). We were all knowledgeable about theory, methodology and practical facilitation and learning techniques, and we collaborated as a team during the whole project. However, the task of ensuring that the techniques were implemented at the 30 conferences was reserved for the consultants, while evaluation fell to the researcher.

The consultants would discuss meeting design with each conference organiser and introduce as much redesign of the learning-meeting variety as was possible, given frequent hesitation and doubt on the part of the organisers. Once these innovations and changes to the programme were negotiated, the consultants would brief the conference moderator on how to introduce and apply the various learning techniques. To support the execution of each conference, consultants, conference organisers and facilitators produced a multi-page 'script', detailing by five-minute intervals all stage directions, speaker introductions, talking points, instructions for learning techniques, breaks, etc. 


\section{Ravn and S. Elsborg}

Fifteen distinct techniques were used. For inclusion in the present report, they had to be significant, used on several occasions, and subject to some measure of evaluation. The eight techniques selected are presented in the next section (two will be added later).

To determine the efficacy of each technique the researcher employed four data sources:

- Evaluative questionnaires completed by conference participants.

- Interviews and conversations with conference organisers and moderators/facilitators after the conferences.

- 'Reflective scripts': During and after the conference, the consultant would observe the facilitator's performance and the subsequent audience reactions and make extensive notes on her copy of the script.

- The researcher's observations, made from his seat in the auditorium.

For a technique to be effective, it must contribute to learning in the manner specified by our theory of the learning conference as a forum for human co-flourishing. How to determine whether learning has taken place, however, is a complex question that finds easy answers only in simplistic theories of learning - such as the transfer model and the associated fact-retention test of the multiple-choice variety. None of the 30 conferences had content that lent itself to such testing; few of the participants would likely have welcomed exit tests of their comprehension of the 'syllabus'; no employers paying for their personnel to attend conferences such as these are known to demand such tests.

So, what proved possible was piggybacking on the evaluation forms that many conference organisers administer at the conclusion of events: We inserted items assessing the new learning techniques employed. We assume that people really do go to conferences to learn and become inspired and pick up ideas and useful tools. So, when respondents say they were satisfied with a particular conference activity, we assume they mean it contributed to their learning. No follow-ups were conducted: thus, participant evaluation was largely confined to Kirkpatrick's (1998) first level of evaluation.

The response categories for all questionnaire items were expressed as Likert-like five-point scales with a neutral midpoint. We report combined percentages in the two top categories (usually 'Very satisfied' and 'Satisfied').

Summing up, the methodology that was used merits the label 'transformative' (Ravn, 2005) in that we attempted to transform the domain of conferences in a research-based way. Unlike consultants and other change agents, we started our change efforts from a theoretically informed basis; one that included a humanistic view of the human potential and pragmatist concepts of knowledge production and learning. Our theory of the learning conference as a forum for human co-flourishing is obviously not a theory of the way the world is, but of the way it could be. As Chris Argyris notes, action researchers must consider such future possibilities and include them in their research: "A complete description of reality requires not only a description of the universe as it is, but also of its potential for significantly reformulating itself" (1982, p.469).

From this transformative theory we derived four design principles and 15-odd learning techniques. Each learning technique is a hypothesis that if participants do what the facilitator invites them to, they will enjoy learning and experience co-flourishing. Implementing a technique is the same as testing the hypothesis it expresses. In eliciting participants' judgement of the technique and observing their behaviour on the floor, we are ascertaining whether the hypothesis is borne out, must be rejected or should be amended. 


\section{Facilitating learning at conferences}

Our research is thus theory-based, hypothetico-deductive (in a fashion), and experimental. Unlike conventional hypothetico-deductive research, we are not concerned with merely explaining reality, but with transforming it, through experiments: the 30 conferences we engaged with.

\section{Results and discussion}

The eight learning techniques selected for presentation are presented under the relevant design principle.

\subsection{Design principle 1: concise presentations}

The point that presentations should be concise and short is widely recognised in the conference industry; many presentations at business conferences now last only 15-20 minutes. The content and presentation style are well-known factors of presentation efficacy (Bienvenu, 1999; Kosslyn, 2007) and were, therefore, not our focus here. We found room for two learning techniques that serve to make presentations concise.

\subsubsection{Technique 1: break up the presentation midway}

A fair number of presentations were originally programmed to last 40-60 minutes. We asked some of these presenters to break up their presentations in two, and most obliged. Various audience activities were introduced in the short breaks provided (as we shall see below), giving participants the chance to discuss the input.

We expected this device to go largely unnoticed by participants and so could not ask a survey question about it. However, observations confirmed the value of these intermissions: many participants perked up visibly. The presenters seemed to enjoy starting up afresh after the break, speaking to more attentive faces. No presenters indicated afterwards that they would have preferred to speak non-stop.

\subsubsection{Technique 2: the presentation as an interview}

To introduce variation into a string of presentations already scheduled for some of the corporate meetings, we suggested that the television journalist hired to moderate the conferences interview one of the presenters. The presenter was freed from his duty to prepare a PowerPoint presentation and would gamely settle into one of the easy chairs provided on stage. From the other chair, the journalist would ask the few questions necessary to get the expert going. The tone of the conversation was generally friendly and appreciative, designed to bring out the presenter's message. After some 10 or 15 minutes, the journalist would turn to the audience, take a few questions and thus sense the participants' interests and try to steer the conversation in that direction.

The conversational style of this kind of 'presentation' presumably helps the participants listen and understand the content. Observation indicates this technique was quite successful. As mentioned, the interviewer was a professional journalist; interviewing proficiency can be safely assumed to be essential here. 


\section{Ravn and S. Elsborg}

\subsubsection{Conclusions about concise presentations}

The two techniques above, one very simple and one requiring real competence, both seemed to be useful to participants' learning. However, they only scratched the surface of the challenge to provide more concise presentations.

\subsection{Design principle 2: active interpretation}

Passive listening to concise presentations only gets you so far. We hypothesised that participants' understanding of presentations is greatly enhanced if they are encouraged to mesh what they hear with what they know already.

A facilitator can make this happen by asking the participants, at appropriate intervals during the day, to spend a few minutes in silent reflection and note-taking or engage in five or ten minutes of reflective conversation with their neighbours. While we failed to persuade any of our partners to try the silent reflection, we did have occasion to test the reflective conversation, which we called a mini-meeting.

\subsubsection{Technique 3: mini-meetings}

A mini-meeting is a conversation between two to four participants, introduced by the conference facilitator during a break in the presentation, or at the end of it. At our request, the facilitators used this device at practically all the conferences, one to five times a day, for periods varying between 2 and 15 minutes.

A mini-meeting calls on people to think actively and articulate their thoughts. The mental ordering process required for people to say something reasonably coherent about a topic most likely improves their understanding of it. What you say out loud is more easily remembered later. Further, listening to another person's interpretation of the presentation may deepen your own understanding. It is a way for conference organisers to begin to include participants' perspectives and giving them more of a voice, literally.

The observational data on this technique are positive. Facilitators and conference organisers were unequivocally pleased with the mini-meetings, not only for the energy emanating from a hundred voices rising within three seconds, but also for the improved quality of the questions raised subsequently. The survey data are a bit more ambiguous. For technical reasons, the item about the mini-meetings was only asked at about half the meetings. From all respondents $37 \%$ considered this opportunity to talk about the presentation to be very good or good, which is one of our lowest scores, and $42 \%$ were indifferent.

When we asked in more general terms about how participants rated 'the opportunities to enter into dialogue with the other participants', $69 \%$ indicated they were good or very good. This dialogue was, for the most part, established through the mini-meetings. This more comprehensive, but also less precise survey item compensates for the fact that the mini-meetings were only five- or ten-minute periods which, due to their brevity, may not make as much of an impression as, say, a 30-minute lecture.

\subsubsection{Technique 4: the question card}

Another way to invite participants to think about the presentation is to ask them to raise questions afterwards. Of course, Q \& A is a conference staple, but sometimes the speaker or the occasion is so intimidating to the audience that no one dares raise a question even 


\section{Facilitating learning at conferences}

when invited. Prior to our project, some of the corporate meetings with a couple of hundred employees went silent after the CEO's hour-long presentation. Typically, the facilitator could handle only about five seconds of this before he pulled his own list of questions to ask; after which the audience was dismissed, to everyone's dissatisfaction.

One of our partners solved this by providing index cards and pens to the audience beforehand. Seated in groups of four or six, participants would be given five minutes to discuss questions they would like to ask and write them down. This invariably produced scores of written questions. They were passed up to the facilitator, who would read the questions and ask them on the spot - or after a break, which allowed for some screening and selection. On other occasions, a co-facilitator would circulate among participants with a microphone and ask them what they wrote on their cards, chatting a little, loosening people up and then inviting them to put their question to the CEO.

The survey response varied. Most participants (56\%) rated this opportunity good or very good; a few $(6 \%)$ were directly against it, some $(38 \%)$ were indifferent. Judging from our observations, the question cards seemed more meaningful in provincial towns than in the capital of Copenhagen, where people generally may be more inclined to speak up. In sum, it proved to be a useful technique for an otherwise passive or shy audience.

\subsubsection{Conclusions about active interpretation}

These techniques proved to be helpful: Participants get to reflect on and talk to others about their understandings and the shy among them are given an opportunity to ask questions and become and active and involved. These are well-known conditions for learning that tend to improve outcomes.

\subsection{Design principle 3: self-formulation}

The techniques that exemplify this design principle allow participants to bring up their own concerns as they relate to the conference topic, not just in response to input from presenters, but as issues worthy of independent consideration.

\subsubsection{Technique 5: participants direct the speaker}

This activity gave participants a chance to decide which topics would be addressed at the conference. During a break in a presentation, the facilitator would have the participants break into groups of four to eight people to discuss where they would like the speaker to go after the break. During this half-hour discussion, the groups would raise the issues they brought to the meeting, develop some shared concerns and write them on a flipchart that was hung on the wall in the auditorium. The speaker would then tour the flipcharts, take note of recurrent issues and address them in a conversational manner during the remainder of his presentation.

This activity was used in one series of corporate orientation meetings for new employees. The HR manager would present his expectations of the new employees and they were asked about their expectations of the bank: What kind of workplace would they like the bank to be? The HR manager, the facilitator and the meeting organisers reported that the flipchart feedback and the plenary conversation were very instructive and useful. This activity has now become a staple at these meetings. 


\section{Ravn and S. Elsborg}

The survey response was middling. Participants were asked to rate the opportunities given to them to enter into dialogue with the speakers and so direct them. Only $36 \%$ rated this good or very good, and $15 \%$ rated it poor or very poor. The researcher's observations tempered this mediocre reception. However, in terms of the observable mood in the audience, this activity changed the tone of the orientation meetings fundamentally, as people were given to the chance to be active and contribute. Participants were livelier and seemed more at ease and attentive during the rest of the day - clear indications that conditions for learning were better.

\subsubsection{Technique 6: two consultants, free of charge}

This activity allows participants to air and get feedback on their professional concerns in a kind of peer coaching session, adapted from the supervision process known as the 'reflecting team' (Andersen, 1991).

After proper instructions, participants are divided into groups of three, A, B and C. The groups spend half an hour together. For the first ten minutes, A presents a current professional challenge that she would like feedback on from B and C. The next ten minutes she goes silent as $\mathrm{B}$ and $\mathrm{C}$ start producing ideas and advice for her. B and $\mathrm{C}$ are instructed to not look at her and to speak this advice to each other, talking appreciatively about her in the third person. Meanwhile, A listens, poker-faced, and takes note of the few ideas she can use. For the last ten minutes, A speaks again. She identifies the best idea and refrains from addressing all the useless ideas; she just lets them go. B and C help her become clearer about the one idea she liked; they are her consultants or coaches, helping her hone her determination about what to do about her professional challenge.

We used this activity in two settings. In one, we told the conference facilitator how to instruct the participants, which she proceeded to do in a fairly superficial way. The activity that resulted appeared to be somewhat like a group discussion of one member's challenge, roaming freely, without the distinctions between phases and the discipline of who speaks when. Nevertheless, the participants enjoyed the chance to talk to each other and to focus on a problem one of them had. Surveyed, $75 \%$ of participants rated it good or very good, while $9 \%$ of participants gave it a negative assessment.

In the other setting, one of our team (the first author) was introduced on stage by the facilitator at the appropriate moment, the idea being that this activity was so complex as to require instruction by an expert. We did this on three occasions: two were failures (participants did not show up at the required time or proved so unwilling during instructions that the activity was doomed), one barely scraped by. Even in the latter case some participants chose not to take part in the activity.

\subsubsection{Conclusions about self-formulation}

When participants were given a bit of a platform to air the concerns that motivated them to go the conference in the first place, were their outcomes improved? 'Participants direct the speaker' was reasonably successful and may be recommended as one of many ways to involve participants in group work.

'Two consultants' did not go down so well. If meeting organisers want participants to play a role this much larger than is commonly the case in conferences, participants must be told and prepped meticulously. An important lesson is the necessity of proper facilitation: trust, humour and the friendly atmosphere that secures participant buy-in. More about this discussed hereafter. 


\section{Facilitating learning at conferences}

\subsection{Design principle 4: networking and knowledge sharing}

The techniques that follow help people learn from each other at conferences, which brings out the substantial knowledge resources present not only on the podium, but in the audience as well. A prerequisite for knowledge sharing with other people is meeting them, and this is a challenge in and of itself.

\subsubsection{Technique 7: meet people}

Having registered in the morning, most participants will find a seat in the auditorium or ballroom and just sit there, waiting to be entertained.

At some of our conferences, we urged the facilitator to help participants get acquainted with each other. After a few introductory remarks, the facilitator would say, "Now, before we begin today's program, I'd like to give you all a chance to meet some of the folks sitting around you. When I say 'Go', please spend five minutes introducing yourselves to three or four people sitting nearby. I'll let you know when the time is up. Go ahead!"

Within seconds, a roar would rise from the auditorium, as everyone found someone to talk to. The change in the room was evident, people would warm themselves up and maybe meet someone they could reconnect with later, thus preparing the group for some useful networking. Afterwards, the facilitator had a better room temperature to work with and could get a head start establishing the safety and trust required for the participants to accept new learning techniques.

The facilitators and meeting organisers reported satisfaction with this small activity. Again, however, the activity was too inconspicuous to qualify for a separate item on the survey.

\subsubsection{Technique 8: a networking lunch}

At many conferences, lunch is taken at long tables of 8-12 seats. Acquaintances band together merrily, while the many people who don't know anyone often sit in islands of silence for the full hour. Hence the need for some facilitated networking.

At some of the conferences, we split the long table into tables of four, on the expectation that no one would be left out of a group that small. Before lunch, the facilitator would ask people to find a table with people they didn't know. Each table had a menu card with conversation starters. People would spread out at the tables, some would ignore the menu cards, while others would pick up the conversation starters and talk as suggested.

The response was mixed. Most people seemed to appreciate the small-table opportunity, but a few reacted strongly to the menu cards, finding them childish and condescending.

At the corporate events for the new employees, lunch used to be a buffet with no tables provided. Being new to the organisation, participants knew no one else and the silence would be deafening as people sought out the walls and hung over window sills alone. We introduced stand-up cocktail tables which enabled people to congregate in groups of about four, and this seemed to stimulate conversation. The survey response was favourable: of all the participants $61 \%$ judged this to be a good or very good opportunity to network and share, while only $9 \%$ said it was poor or very poor. Facilitators and meeting organisers quickly picked up on this and institutionalised it for all further conferences. 


\section{Ravn and S. Elsborg}

\subsubsection{Conclusions about networking and knowledge sharing}

The two minor and inconspicuous techniques in this section were quite successful, by observer standards. At the end of the day, some participants probably don't recall having been exposed to them, while others, as anecdotal evidence suggested, thought that the little twist provided by this or that technique made the day different and pleasant. The techniques can be implemented quite easily, but we do not wish to claim they are major contributions to learning at conferences.

\subsection{Design principle 5: competent facilitation}

A major responsibility of the traditional conference host or moderator is to execute the programme promptly: Start and finish the day and every presentation on time, introduce and thank speakers and moderate Q-and-A.

For the learning conference, timekeeping is still of the essence. In addition, however, a facilitator must be able to create a safe and friendly atmosphere conducive to learning. Participants arrive at the conference expecting the usual string of lectures and passive listening. If the conference organisers want to stimulate learning in new ways, participants must be nudged and goaded to do things which at first may seem odd, contrived or even unpleasant. This requires tact, handholding and some measure of charm on the part of the facilitator.

The facilitator must establish her presence and explain her function first thing in the morning: "My role today is to make sure that you all get as much as possible out of the conference and the other resources and people that are present in this room. I hope to be able to give you all the chance to discuss and learn and be inspired as much as you expect."

Here are two routines relevant to this task that we helped the facilitators develop or refine:

- Cherry-picking: When break-out groups would return to the plenary, the facilitator would not ask them all to report on their work, as this becomes boring after three or four groups. She told the groups beforehand, "We will hear from some of you; I will cherry-pick your feedback". Groups that had been creative and happy waved their hands and were heard, and the few unproductive groups were let off the hook. The facilitator is not obliged to plough through any list of group representatives to the bitter end, but can stop before the energy in the room drops.

- Bundling questions: During Q-and-A some of our experienced facilitators would take several questions from the floor, chat with those asking questions and bundle a few questions for the presenter to answer. Often, this softened up the room and made people more comfortable; it sharpened diffuse questions and gave the presenter a minute to prepare his answers.

At most of the conferences, participants were asked to rate the facilitator's ability to create dialogue between participants and presenters. At a number of course-like conferences, where facilitators used cherry-picking as well as bundling questions, facilitators were rated 'Good' or 'Very good' by $93 \%$ of respondents and 'Poor' and 'Very poor' by $0 \%$. Corresponding numbers for traditional conferences, where facilitators did not use these routines, were $55 \%$ and $6 \%$, respectively. This comparison must be taken with a grain of salt, since the two types of conferences differed along a 


\section{Facilitating learning at conferences}

number of other, possibly confounding dimensions, such as overall facilitator skill. Which, however, only goes to emphasise the point: learning techniques may look fine on paper, they may even work in one conference, but if they are not introduced and executed skilfully by a facilitator who can persuade his audience, they may come to naught.

\section{Conclusions and implications for practice}

At 30 conferences, typically involving some 100-200 participants each, we introduced a number of learning techniques intended to increase participant involvement and learning. Ten of those techniques were reported here; the majority of them were received well by the participants. They may be assumed to have contributed positively to participants' learning and, in their own small way, to the mutual inspiration that we identified as an essential component of the human co-flourishing posited as the ideal for the conference as a learning forum.

Our data show that you can indeed change and improve the traditional, one-way communication format of the traditional conference. Only small steps proved possible in our conferences, but these small steps often had surprisingly large effects. A conference that starts by letting participants spend five minutes saying hello to strangers seated near them and then, an hour later, allows for ten minutes of conversation in pairs before Q-and-A will feel quite different and refreshing to most people. This effect may be created by simple means that require only an investment of 15 or 20 minutes out of a full day's conference.

Yet, we also discovered that techniques such as these, and especially more complex one like the 'Two consultants, free of charge', must be introduced by a competent host or facilitator who has gained the participants' trust, so that they willingly go along with the innovations introduced. After the 30 conferences, this led us to propose a fifth design principle, competent facilitation.

On the whole, our line of experiments bore out the four design principles - with the important qualification that the art of facilitation needs more attention than we originally allowed for. Our observations and other data sources strongly indicate that there is good sense in conceiving of the conference as a learning forum that not only requires good input (in the form of substantial and entertaining presentations), but also facilitated processes and activities that induce people to interpret actively what they hear, relate it to their ongoing interests and projects, and to share inspiration and knowledge with each other at the conference.

The major purpose of the transformative research methodology employed was to produce practical knowledge that can help practitioners improve and transform their domains. Thus, our research is the implications for practice. We couched our interventions in the form of methods and techniques, making a major point out of formulating them in the how-to form that practitioners generally find applicable (in Elsborg and Ravn, 2007). However, as was underscored repeatedly during the project: In themselves, techniques are not enough; they must be adapted to the situation at hand and applied through competent facilitation. 


\section{Ravn and S. Elsborg}

\section{References}

Andersen, T. (Ed.) (1991) The Reflecting Team, Norton, New York.

Argyris, C. (1982) Reasoning, Learning, and Action, Jossey-Bass, San Francisco, CA.

Aristotle (1962) Nicomachean Ethics (Trans. M. Oswald), Bobbs-Merrill, Indianapolis, IN.

Baburoglu, O. and Ravn, I. (1992) 'Normative action research', Organization Studies, Vol. 13, No. 1, pp.19-35.

Bienvenu, S. (1999) The Presentation Skills Workshop, The American Management Association, Washington, DC.

Bligh, D.A. (2000) What's the Use of Lectures? 6th ed., Jossey-Bass, San Francisco, CA.

Brown, J., Isaacs, D. and the World Cafe Community (2005) The World Café, Berrett-Koehler, San Francisco, CA.

Bunker, B.B. and Alban, B.T. (1995) Large Group Interventions, Jossey-Bass, Berrett-Koehler, San Francisco, CA.

Capes, M. (1960) Communication or Conflict: Conferences, Their Nature, Dynamics, and Planning, Association Press, New York.

Chapman, D.D., Wiessner, C.A., Storberg-Walker, J. and Hatcher, T. (2007) 'New learning: a different way of approaching conference evaluation', Knowledge Management Research \& Practice, Vol. 5, pp.261-270.

Cobb, P., Confrey, J., diSessa, A., Lehrer, R. and Schauble, L. (2003) 'Design experiments in educational research', Educational Researcher, Vol. 32, No. 1, pp.9-13.

Deci, E.L. and Ryan, R.M. (2000) 'The "what" and "why" of goal pursuits: human needs and the self-determination of behavior', Psychological Inquiry, Vol. 11, No. 4, pp.227-268.

Dewey, J. (1929) The Quest for Certainty: A Study of the Relation of Knowledge and Action, Minton, Balch, New York.

Dreyfus, H. and Dreyfus, S. (1986) Mind over Matter, Macmillan, New York.

Elsborg, S. and Ravn, I. (2007) Learning Meetings and Conferences in Practice, People's Press, Copenhagen.

Illeris, K. (2004) Adult Education and Adult Learning, Krieger, New York.

Hansen, N.J. (2011) Conferences as Dramaturgical Learning Spaces, PhD Dissertation, Department of Learning, Danish School of Education, Aarhus University.

Hatcher, T., Wiessner, C.A., Storberg-Walker, J. and Chapman, D. (2006) 'How a research conference created new learning', Journal of European Industrial Training, Vol. 30, No. 4, pp.256-271.

Kirkpatrick, D. (1998) Evaluating Training Programs: The Four Levels, 2nd ed., Berrett-Koehler, San Francisco, CA.

Kosslyn, S. (2007) Clear and to the Point. 8 Psychological Principles for Compelling PowerPoint Presentations, Oxford University Press, New York.

Maslow, A. (1968) Toward a Psychology of Being, 2nd ed., Van Nostrand, New York.

Nielsen, L.D. (2006) 'The methods and implications of action research: a comparative approach to search conferences, dialogue conferences and future workshops', in Nielsen, K.A. and Svendsen, L. (Eds): Action and Interactive Research, Shaker, Maastricht, The Netherlands, pp.89-116.

Paul, E.F., Miller, F.D. and Paul, J. (Eds) (1999) Human Flourishing, Cambridge University Press, New York.

Pinker, S. (2002) The Blank Slate, Viking, New York.

Ravn, I. (2005) 'Transformative theory in social research: the case of the learning conference', 18-20 August, Dansk Sociologkongres, Roskilde University.

Ravn, I. (2007) 'The learning conference', Journal of European Industrial Training, Vol. 31, No. 3, pp.212-222. 


\section{Facilitating learning at conferences}

Romme, A.G.L. (2003) 'Making a difference: organization as design', Organization Science, Vol. 14, pp.558-573.

Rothman, J. and Thomas, E.J. (Eds) (1994) Intervention Research, The Haworth Press, New York.

Schechter, W. (2001) United Nations-Sponsored World Conferences, United Nations University Press, Tokyo, Japan.

Schon, D. (1983) The Reflective Practitioner, Basic Books, New York.

Shannon, C.E. and Weaver, W. (1949) The Mathematical Theory of Communication, University of Illinois, Urbana, IL.

United Nations Development Programme (2005) Human Development Report 2005, Oxford University Press, Oxford.

van Aken, J.E. (2005) 'Management research as a design science', British Journal of Management, Vol. 16, No. 1, pp.19-36.

Vygotsky, L.S. (1978) 'Mind in Society', in Cole, M., John-Steiner, V., Scribner, S. and Souberman, The Development of Higher Psychological Processes, Harvard University Press, Boston, MA.

Weedman, J. (1999) 'Conversation and community: the potential of electronic conferences for creating intellectual proximity in distributed learning environments', Journal of the American Society for Information Science, Vol. 50, No. 10, pp.907-928.

Wiessner, C.A., Hatcher, T., Chapman, D. and Storberg-Walker, J. (2008) 'Creating new learning at professional conferences: an innovative approach to conference learning, knowledge construction and programme evaluation', Human Resource Development International, Vol. 11, No. 4, pp.367-383.

\section{Note}

1 We acknowledge our colleagues Nina Tange and Malene Rix. 